\section{Firm resistance to splitting of university research and teaching}

London

THE British government's proposals for reorganizing higher education would lead to a system with a limited number of elite universities plus a large number of institutions that will be little more than teaching factories, the new chairman of the Committee of Vice-Chancellors and Principals, Sir Mark Richmond, has warned.

The government last week issued consultative papers calling for comments on a controversial new university funding approach based on contracts, with the abolition of the block grants system run by the University Grants Committee (UGC) and its replacement by a new University

\section{Embryo guidelines opposed by clinics}

\section{London}

NEw guidelines forbidding donation of eggs by relatives of infertile patients, and the transfer of more than four embryos at a time, were issued last week by the British body that licenses centres carrying out in vitro fertilization and embryo research. ing Authority (VLA) in conflict with one London clinic, the Wellington Humana Hospital, which last week revealed that two patients who had received eggs from their sisters had recently given birth to twins. The VLA's ruling is in line with its principle that the anonymity of the donor is paramount in the interests of the child.

The licensing authority will meet representatives from the $\mathbf{2 8}$ clinics working on in vitro fertilization in September to receive assurances that the guidelines will be observed. But without legislation, the only action the VLA can take against clinics that its approval; it cannot prevent them from operating.

Announcing the new guidelines, VLA chairman Dame Mary Donaldson stressed the urgent need for legislation and for the establishment of a statutory body with a qualified inspectorate, but held out little hope for progress in the near future.

The VLA was set up two years ago by the Royal College of Obstetricians and Gynaecil following the completion of the Warnock Report on human fertilization and embryology, which recommended a statutory licensing authority.

Although accepting that some delay was desirable before legislation, the VLA is finding it increasingly difficult to retain sufficient control over the rapidly growing field. The new rulings put the Voluntary Licensrefuse to obey the guidelines is to withdraw cologists and the Medical Research Coun-
Funding Council (UFC) closely tied to industry. A report recommending the recr sanization of the university system for sciences has also been released, with what Richmond termed "considerable implications for the way the university system will be run".

The Earth Sciences Review committee report, published last week by the University Grants Committee (see Nature 326, $813 ; 1987)$, recommends three levels of institutions - a top group of 10 or 12 universities equipped for international research and teaching, a middle group with research at a lower level without sophisticated equipment, and a bottom group offering only low-level teaching. Although the report of the committee, chaired by Professor Ron Oxburgh, was intended to apply only to geology, its covering letter from the UGC notes that this reorganization has "implications for the future reorganization of other subjects, particularly chemistry and physics". The UGC is asking for reaction from universities, pointing out that implementation would "require close cooperation".

Although some scientists would welcome the concentration of top research work in a few institutions, there are concerns about separating the sciences. "Can you be a top-class research institution if you have only biology, for instance, but not chemistry?" asked Richmond. "I think you've got to have both."

The system of contracting for funding with the new UFC, set out in the consultative paper, is seen as giving the government increasing power over the direction of universities. The report includes no mechanism for universities to advise the government on their needs, the outgoing chairman of the vice chancellors' committee Mr Maurice Shock said. But it does spell out that the government will offer guidance on "the nation's needs with regards to the size and broad balance of the university system".

Contracts for funding could take one of three forms: a single, comprehensive contract covering all of an institution's activities; a subdivision into separate faculties or departments or even separate courses; or a mesh of these two approaches. "The ferocity of the response to this contracting approach will depend on which option is chosen," Richmond said. "But the touchstone will be value for money. The pressure will be there to do things as cheaply as possible." The intention is to encourage universities to attract contracts from private sources.

The vice chancellors' committee will discuss its reaction to the consultative papers later this month. "I hope these really are consultative documents and that the government will listen to reasoned response," Shock said. But the documents make it clear that legislation to implement the new UFC will be introduced soon, and comments are being sought for "the framing of detailed legislative provisions."

\section{Marc Aaronson (1940-1987)}

MARc Aaronson died in an accident at the Mayall 4-m telescope of the National Optical Astronomy Observatories, United States, on 30 April. He received his first degree from Caltech in 1972 and his doctorate from Harvard in 1977, where he worked with several astronomers, including John Danziger, Jay Frogel and Eric Persson. He took part in the effort to understand the infrared energy distribution of galaxies in terms of their stellar populations, and wrote a thesis on the infrared properties of spiral galaxies, showing the increasing contribution of young stars to the integrated optical emission of later type galaxies.

In 1977 he went to the University of Arizona, Tucson, to work. He made several important discoveries, the first of which was the usefulness of the infrared Tully-Fisher relation in measuring redshift-independent relative distances of galaxies. He led a collaboration with Greg Bothun, John Huchra, Paul Schechter, Robert Schommer, Woodruff Sullivan, Brent Tully, myself and others. With these more precise distances to galaxies he recognized the signal of the Virgocentric flow within the Local Supercluster, that is, the deceleration of the Hubble flow locally by the mass centred on the Virgo cluster.

In 1978, Aaronson proposed that we follow up the suggestion that carbon stars were responsible for the peculiar optical and infrared colours of some globular clusters in the magellanic clouds. As a result of frequent trips to Cerro Tololo Interamerican Observatory we were able to show that carbon stars were a characteristic of intermediate age stellar populations, as predicted by some theoretical models of stellar evolution.

Aaronson's third important discovery surprised everyone. He measured the velocity dispersion of carbon stars in dwarf spheroidal galaxies, by means of high resolution spectroscopy at the Multiple Mirror Telescope. He found a velocity dispersion significantly greater than the expectations from globular clusters, indicating that even the tiniest dwarf galaxies have dark halos. These results favour cold dark matter as the material comprising such halos. 